\title{
KELAYAKAN PENGEMBANGAN JAGUNG PIPILAN UNTUK MEMENUHI KEBUTUHAN INDUSTRI PAKAN TERNAK DI PROVINSI BANTEN
}

\section{THE DEVELOPMENT FEASIBILITY OF CORN TO MEET THE NEEDS OF ANIMAL FEED INDUSTRY IN BANTEN PROVINCE}

\author{
DIAN ANGGRAENI ${ }^{1}$, ALIUDIN ${ }^{1}$, SETIAWAN SARIYOGA ${ }^{1}$, ANTON EKA PRASETIA $^{2}$ \\ 1. Dosen Fakultas Pertanian Untirta \\ 2. Mahasiswa S2 Ilmu Pertanian Pascasarjana Untirta \\ Email : diananggraeni@untirta.ac.id
}

\begin{abstract}
ABSTRAK
Ketersediaan sumberdaya lahan, kebijakan pemerintah yang mendukung, serta meningkatnya permintaan jagung terutama untuk bahan baku pakan ternak merupakan alasan utama bahwa pengembangan komoditi jagung sangat diperlukan. Langkah strategis ke arah pengembangan usaha sangat penting dan dapat meyakinkan petani untuk mengambil langkah strategis. Penelitian ini bertujuan untuk (1) mengkaji nilai investasi yang dibutuhkan dalam usahatani jagung, (2) mengetahui kelayakan usaha yang perlu dilakukan untuk menyelenggarakan bisnis jagung. Metode yang digunakan dalam penelitian ini adalah metode survey dengan lokasi yang ditentukan secara sengaja yaitu di Provinsi Banten dengan 3 Kabupaten sebagai sentra komoditas jagung, yakni Kabupaten Serang, Pandeglang dan Kabupaten Lebak. Teknik sampling yang digunakan adalah Two Stage Cluster Random Sampling. Jumlah sampel dari Kabupaten Serang sebanyak 45 orang, Kabupaten Pandeglang 30 orang dan Kabupaten Lebak sebanyak 45 orang. Jadi total sampel keseluruhan 120 orang dari 1.388 orang populasi petani jagung di Provinsi Banten. Jenis data dalam penelitian ini adalah data primer dan data sekunder. Data primer diperoleh dengan wawancara langsung ke petani jagung dengan menggunakan kuesioner, sementara data sekunder diambil melalui studi literatur dan dari instansi yang terkait. Metode analisis data dengan menggunakan analisis NPV, IRR dan Payback Period. Hasil penelitian menunjukkan bahwa jumlah investasi yang diperlukan untuk kelayakan budidaya jagung sebesar Rp.19.654.890, nilai NPV Rp. 1.713.365.673.996, IRR sebesar 115,65 dan Payback Period selama 1 tahun lebih atau tepatnya 1 tahun 5 bulan 9 hari. Berdasarkan hasil penelitian menunjukkan bahwa bisnis jagung pipilan di Provinsi Banten layak untuk dikembangkan.
\end{abstract}

Kata Kunci: Produksi, Kelayakan, Pengembangan, Komoditi Jagung.

\section{ABSTRACT}

The availability of land resources, supportive government policies, and the increasing demand for corn, especially for animal feed raw materials, are the main reasons that the development of corn commodity is very necessary. Strategic steps towards business development are very important and can convince farmers to take strategic steps. This study aims to (1) examine the value of the investment needed in corn farming, (2) determine the feasibility of the business that needs to be done to run a corn business. The method used in this study is a survey method with a location that is deliberately determined, namely in Banten Province with 3 districts as centers of corn commodities, namely Serang, Pandeglang and Lebak districts. The sampling technique used is Two Stage Cluster Random Sampling. The number of samples from Serang district was 45 people, Pandeglang district 30 people and Lebak district as many as 45 people. So, the total sample is 120 people from 1,388 corn farmer population in Banten Province. The types of data in this study are primary data and secondary data. Primary data was obtained by direct interviews with corn farmers using a questionnaire, while secondary data was obtained through literature studies and from related agencies. Data analysis method using NPV, IRR and Payback Period analysis. The results showed that the amount of investment required for the feasibility of corn cultivation was Rp. 19,654,890, the NPV value was Rp. 1,713,365,673,996, IRR of 115.65 and Payback Period for more than 1 year or to be precise 1 year 5 months 9 days. Based on the results of the study, it shows that the shelled corn business in Banten Province is feasible to develop.

Keywords: Production, Feasibility, Development, Corn Commodity. 


\section{PENDAHULUAN}

Jagung merupakan komoditas yang multiguna, karena hampir seluruh bagian dari tanaman jagung mempunyai potensi nilai ekonomis. Biji jagung pipilan sebagai produk utamanya merupakan bahan baku utama (sekitar 50 persen) untuk industri pakan, selain dapat dikonsumsi langsung dan sebagai bahan baku industri pangan. Daun, batang, kelobot, tongkolnya dapat dipakai sebagai pakan ternak dan pemanfaatan lainnya. Dengan kegunaan yang beragam tersebut jagung memiliki nilai ekonomi yang sangat menarik. Fungsi dan manfaat jagung yang besar tersebut menjadikan jagung komoditas pangan yang menjadi perhatian penting negara setelah padi.

Jagung bagi Provinsi Banten merupakan komoditi yang memiliki prospek yang sangat baik dengan pangsa pasar yang luas, terutama untuk pakan ternak. Dari total pabrik pakan ternak di wilayah Indonesia, 80 persen lokasi proses produksinya ada di wilayah Kabupaten Serang. Di sisi lain, daya dukung agroekosistem Provinsi Banten sangat sesuai untuk produksi jagung, tetapi peluang ini belum dimanfaatkan oleh petani dan pemerintah Provinsi Banten. Padahal pengembangan jagung memberikan multiplier efek yang luas bukan saja terhadap peningkatan pendapatan petani tetapi juga terhadap pertumbuhan wilayah.

Pokok permasalahan yang dihadapi Provinsi Banten dalam pengembangan jagung meliputi: (1) permasalahan luas garapan petani yang rata-rata hanya 0,2 sampai dengan 0,5 $\mathrm{Ha}$, keterbatasan modal (akses dan ketersedian teknologi terutama teknologi pengeringan, efisiensi input, penyimpanan dan gudang, dukungan kelembagaan keuangan). Pengembangan suatu komoditi pertanian tidak terlepas dari masalah karakteristik tanaman, tidak terkecuali jagung. Komoditi jagung yang dipilih untuk dikembangkan harus memiliki karakteristik yang unggul (memiliki produktivitas yang tinggi dan genjah). Dua karakteristik ini dimiliki oleh jagung yang disebut jagung hibrida. Pengembangan jagung hibrida akan mampu meminimalisir risiko dan ketidakpastian dari harga dan iklim yang secara tidak langsung akan meningkatkan efsisiensi penggunaan faktor produksi. Efisiensi penggunaan input produksi merupakan solusi untuk meningkatkan permasalahan daya saing komoditi jagung.

Pertumbuhan dan perkembangan Jagung di Provinsi Banten setidaknya dapat mengintegrasikan sektor pendukung yang ada di hulu dengan sektor hilir. Untuk membangun integrasi ini langkah awal yang strategis dibutuhkan penguatan sektor hulu. Penelitian ini bermaksud mengkaji kebutuhan investasi yang memberikan kelayakan usaha untuk pengembangan komoditi jagung tersebut.

\section{METODE PENELITIAN \\ Tempat dan Waktu}

Lokasi penelitian ditentukan secara sengaja (purposive) di Provinsi Banten dengan tiga kabupaten sebagai sentra komoditas jagung, yaitu Kabupaten Serang, Pandeglang dan Kabupaten Lebak. Penelitian ini dilakukan secara survey dengan waktu penelitian mulai bulan April 2021 sampai dengan bulan Juli 2021.

\section{Metode Penentuan Sampel}

Teknik sampling yang digunakan adalah Two Stage Cluster Random Samping, dengan tahapan sebagai berikut: pertama menentukan 3 kabupaten sebagai sentra produksi jagung yaitu Kabupaten Serang, Pandeglang dan Kabupaten Lebak. Kedua memilih satu kecamatan secara sengaja dari 3 kabupaten yang sudah ditentukan yaitu Kecamatan Gunung Sari untuk Kabupaten Serang (507 petani), Kecamatan Cadasari untuk Kabupaten Pandeglang (355 petani) dan Kecamatan Malingping untuk Kabupaten Lebak (526 petani). Jadi total populasi sebanyak 1.388 orang petani jagung, kemudian dengan menggunakan rumus simple random sampling diperoleh total sampel sebanyak 120 orang petani. Penentuan jumlah sampel dari masingmasing Kabupaten ditentukan secara proporsional sehingga dari Kabupaten Serang sebanyak 45 orang, Kabupaten Pandeglang 30 orang dan Kabupaten Lebak 45 orang petani jagung.

\section{Jenis dan Sumber Data}

Jenis data yang dipergunakan dalam penelitian ini adalah data primer dan data sekunder. Data primer diperoleh melalui wawancara langsung dengan petani jagung, data sekunder melalui proses membaca dan mengambil sumber dan keterangan yang diperlukan dari laporan penelitian terdahulu, buku dan juga instansi yang terkait dengan penelitian. 


\section{Metode Pengolahan Data}

Metode pengolahan data dilakukan secara deskriptif kuantitatif yaitu dengan menghitung nilai investasi yang dibutuhkan untuk pengembangan bisnis jagung dan dari aspek finansial, dengan menghitung $\mathrm{Net}$ Present Value (NPV), Internal Rate of Return (IRR) dan Payback Periode (PBP).

\section{Metode Analisis Data}

Mengetahui besarnya biaya investasi dalam pengembangan komoditas jagung, dianalisis dengan cara deskriptif kuantitatif

Mengetahui kelayakan usaha, dengan analisa kelayakan diantaranya: Net Present Value (NPV), Internal Rate of Return (IRR) dan Payback Period (PBP).

1. Net Present Value (NPV)

$$
N P V=\sum_{t=1}^{t=n} \frac{B t-C t}{(1+i)}
$$

Keterangan :

$B t=$ manfaat yang diperoleh pada tahun ke-i

$C t=$ biaya yang dikeluarkan pada tahun ke-i

$t=1,2,3, \ldots \mathrm{n}$

$n=$ jumlah tahun

$i=$ tingkat bunga (faktor diskonto)

Dengan kriteria :

a. Apabila nilai NPV yang dihasilkan lebih besar dari nol, berarti proyek dapat menghasilkan keuntungan

b. Apabila nilai NPV yang dihasilkan sama dengan nol, berarti proyek akan mengembalikan biaya sebesar oportunity cost faktor produksi modal

c. Apabila nilai NPV kurang dari nol, proyek tersebut tidak menguntungkan

\section{Internal Rate Of Return (IRR )}

Tingkat pengembalian internal (IRR) adalah tingkat diskonto yang dapat membuat manfaat sekarang netto dari arus manfaat netto tambahan atau arus uang tambahan sama dengan nol. Tingkat tersebut adalah tingkat bunga maksimum yang dapat dibayar oleh proyek sehubungan dengan sumberdaya yang digunakan. Hal ini disebabkan proyek juga membutuhkan dana tersebut untuk biaya -biaya operasi dan investasi serta proyek baru sampai pada tingkat pulang modal. Formulasi matematisnya sebagai berikut:

$$
I R R=\sum_{t=1}^{t=n} \frac{B t-C t}{(1+i)^{i}}=0
$$

Keterangan :

$B t=$ manfaat yang diperoleh pada tahun ke-i

$C t=$ biaya yang dikeluarkan pada tahun ke-i

$t=1,2,3, \ldots \mathrm{n}$

$n=$ jumlah tahun

$i=$ tingkat bunga (faktor diskonto)

3. Payback Period (PBP)

$$
P B P=\frac{\text { Investasi }}{\text { Keuntungan }}
$$

\section{HASIL DAN PEMBAHASAN}

\section{A. Penyertaan Modal yang Dibutuhkan untuk Bisnis Jagung di Provinsi Banten}

\section{Luas Tanam Budidaya Jagung}

Luas tanam petani sampel bervariasi, dengan kisaran 0,5 ha sampai dengan 30 ha. Jenis lahan di tiga lokasi penelitian berupa lahan kering. Terdapat perbedaan sistem tanam di tiga wilayah penelitian yaitu di Kabupaten Serang sistem tanam yang digunakan monokultur dengan memanfaatkan lahan tidur, sistem tanam di Kabupaten Pandeglang menggunakan sistem monokultur dengan menggunakan lahan milik sendiri, di Kabupaten Lebak mengunakan sistem polikultur, tanaman jagung ditanam diantara tanaman palawija lain seperti singkong dan kacang hijau. Rata-rata luas tanam jagung 2,28 ha, jumlah total luas tanam petani sampel 27,9 ha.

\section{Penggunaan Pupuk Kandang}

Pupuk kandang merupakan pupuk yang penting dalam budidaya jagung di lokasi penelitian. Pupuk kandang yang digunakan yaitu pupuk kotoran ayam. Pupuk ini diperoleh dari wilayah setempat, di peternakan ayam. Kisaran penggunaan pupuk organik antara $50 \mathrm{~kg}$ sampai dengan $5000 \mathrm{~kg}$ per musim. Volume Penggunaannya bervariasi sesuai dengan luas tanam jagung petani sampel. Total penggunaan pupuk kandang $99.850 \mathrm{~kg}$ per musim pada tahun penelitian. Rata-rata per petani sampel mengunakan pupuk $364 \mathrm{~kg}$ per ha. Pupuk organik yang diaplikasikan petani jagung ditentukan oleh luas tanam. Berdasarkan hasil wawancara kesiapan modal di awal rencana penanaman pun secara tidak langsung berpengaruh terhadap penggunaan pupuk organik.

Variasi biaya yang dikeluarkan untuk biaya pupuk organik oleh masing-masing sampel berkesesuaian dengan variasi volume 
penggunaan pupuk organik. Kisaran biaya yang dikeluarkan untuk pupuk organik petani sampel antara Rp.35.000 sampai dengan Rp. 3.500.000.

\section{Penggunaan Pupuk Urea}

Pupuk urea merupakan pupuk yang penting diaplikasikan dalam budidaya jagung. Penggunaan pupuk urea relatif berfluktuasi, hal ini disebabkan oleh kemampuan permodalan diantara petani sampel berbeda-beda. Penggunaan pupuk urea berada pada kisaran 50 $\mathrm{kg}$ sampai dengan $750 \mathrm{~kg}$, dengan pemakaian urea rata-rata setiap petani $79,15 \mathrm{~kg}$. Total pemakaian yang digunakan petani $21.680 \mathrm{~kg}$. Biaya pupuk urea yang dikeluarkan petani pun bervariasi sesuai dengan volume yang diaplikasikan dan luas tanam jagung. Untuk satu musim aplikasi mengeluarkan biaya yang terendah Rp. 100.000, dan biaya yang yang tertinggi yang dikeluarkan petani Rp. 1.320.000.

\section{Pupuk NPK}

Pupuk NPK yang diaplikasikan petani relatif bervariasi, aplikasi terendah $65 \mathrm{~kg}$ dan aplikasi tertingi $585 \mathrm{~kg}$. Variasi aplikasi volume pupuk yang digunakan linier dengan biaya yang dikeluarkan petani, kisaran biaya yang dikeluarkan antara Rp.169.000 sampai dengan Rp.1.521.000. Variasi pupuk NPK yang diaplikasikan petani dipengaruhi oleh ketersediaan modal dan luas tanam petani.

Variasi penggunaan pupuk NPK tersebut linier dengan biaya yang dikeluarkan, jumlah biaya total untuk pupuk NPK Rp. 77.977.500, biaya rata-rata per petani Rp. $284.693,32$. Total pupuk urea yang diaplikasikan $28.184 \mathrm{~kg}$, volume rata-rata per petani 102,89 $\mathrm{kg}$.

\section{Tenaga Kerja}

Tenaga kerja yang bekerja di usahatani jagung pipilan bervariasi. Rata-rata setiap petani menggunakan tenaga kerja 30,88 HKP. Jumlah total tenaga kerja yang digunakan 2.212.887,92 HKP. Petani selain menggunakan tenaga kerja luar keluarga petani, juga menggunakan tenaga kerja dari dalam keluarga. Dalam analisa ini upah tenaga kerja dari luar keluarga dan upah tenaga kerja dari dalam keluarga tidak ada perbedaan.

Penggunaan tenaga kerja terendah 15 HKP dan penggunaan tenaga kerja tertinggi 165 HKP. Biaya yang dikeluarkan untuk membayar tenaga kerja yang terkecil $\mathrm{Rp}$. 975.000 dan biaya terbesar yang dikeluarkan untuk membayar tenaga kerja Rp. 10.725.000, dengan upah rata-rata Rp.65.000 per HKP.

Berdasarkan komponen-komponen biaya tersebut selanjutnya diproyeksikan untuk penyertaan modal untuk kelayakan komersialisasi dan produksi jagung pipilan. Angka proyeksi ini disesuaikan kembali dengan ketentuan-ketentuan pada kelayakan proyek. Untuk lebih jelasnya penyertaan modal dapat dilihat pada Tabel 1.

Tabel. 1. Penyertaan Modal untuk Komersialisasi dan Produksi Jagung Pipilan

\begin{tabular}{llr}
\hline \multicolumn{1}{c}{ Bahan baku dan alat } & Peruntukkan & Kebutuhan Dana (Rp) \\
& Persiapan & 500.000 \\
& Perijinan & 1.500 .000 \\
\hline \multirow{2}{*}{ Mesin } & Hand Traktor & 7.699 .890 \\
& Pompa & 3.605 .000 \\
& Hand Sprayer & 3.605 .000 \\
\hline \multirow{2}{*}{ Peralatan } & Peralatan Produksi & 2.020 .000 \\
& Peralatan penunjang & 725.000 \\
\hline \multirow{2}{*}{ Modal Kerja } & Total Investasi & 19.654 .890 \\
& Bahan Baku dan penunjang & \\
& Gaji Karyawan Produksi & 58.000 .000 \\
& Biaya Overhead & 6.900 .000 \\
& BiayaPemasaran & 332.958 .235 \\
\hline & Total & 417.513 .125 \\
\hline & Cadangan 10 \% & 41.751 .313 \\
\hline
\end{tabular}


Berdasarkan hasil analisis menunjukkan bahwa untuk menjamin kelayakan komersialisasi dan produksi jagung pipilan dibutuhkan penyertaan modal $\mathrm{Rp}$. 459.264.438. Total penyertaan modal tersebut sudah termasuk cadangan sebesar 10 persen. Investasi yang dibutuhkan Rp. 19.654.890 dan modal kerja yang harus tersedia Rp. 417.513.125.

\section{B. Aspek Finansial}

Analisis kriteria kelayakan usaha dilakukan untuk menentukan apakah kegiatan bisnis/usaha produksi jagung pipilan layak diusahakan selama umur proyek. Perhitungan kriteria investasi menggunakan metode cash flow, dimana seluruh penerimaan selama 5 tahun ke depan didiskontokan pada masa kini. Analisis kriteria kelayakan yang digunakan dalam penelitian ini adalah menggunakan 3 (tiga) kriteria, yaitu NPV, IRR dan PBP, yang dapat dilihat pada Tabel 2 .

Tabel 2. Kriteria Kelayakan Komersialisasi dan Produksi Jagung Pipilan

\begin{tabular}{clcc}
\hline No & \multicolumn{1}{c}{ Kriteria } & Hasil & Keterangan \\
\hline 1 & Net Present Value (NPV) & 1.713 .365 .673 .996 & Layak \\
2 & Internal Rate of Return (IRR) & 115,65 & Layak \\
3 & Payback Period (PBP) & 17,9 & layak \\
\hline
\end{tabular}

NPV suatu proyek adalah selisih PV arus penerimaan dengan $\mathrm{PV}$ arus biaya. Berdasarkan hasil perhitungan, diperoleh NPV $\mathrm{Rp}$ 1.713.365.673.996. Nilai tersebut menunjukkan bahwa arus masuk produksi jagung pipilan selama periode 5 tahun pada tingkat bunga yang ditetapkan lebih besar dari pada arus kas keluarnya, sehingga bisnis/produksi jagung pipilan yang dilakukan ini menguntungkan dan layak diimplementasikan dalam jangka panjang karena NPV yang dihasilkan lebih besar dari nol $(\mathrm{NPV}>0)$.

IRR menunjukkan kemampuan suatu proyek untuk menghasilkan tingkat pengembalian modal bagi perusahaan yang melakukan investasi selama proyek berlangsung dan dinyatakan dalam satuan persen. Nilai IRR yang diperoleh pada usaha/bisnis komersialisasi produksi jagung pipilan yaitu sebesar 115,65 persen (DF $>14$ $\%)$ artinya proyek yang dilakukan oleh perusahaan memiliki tingkat pengembalian proyek terhadap investasi yang dikeluarkan sebesar 115,65 persen . Hal ini menunjukkan bahwa kemampuan pengembalian modal yang digunakan lebih besar dari tingkat discount rate yang digunakan. Dari hasil analisis diatas dapat disimpulkan bahwa proyek produksi dan komersialisasi jagung pipilan sangat layak untuk dilaksanakan.

Payback periode (PBP) atau masa pengembalian investasi merupakan perhitungan terhadap lamanya waktu yang diperlukan oleh suatu proyek untuk dapat mengembalikan biaya investasi awal. Hasil analisis tingkat pengembalian investasi (payback period) yang berdasarkan nilai sekarang dengan tingkat diskonto dengan persentase yang sudah ditentukan, diperoleh nilai PBP sebesar 17,9. Hal ini memperlihatkan bahwa untuk memperoleh kembali nilai investasi yang telah dilakukan diperlukan waktu selama lebih dari 1 tahun, yaitu 1 tahun 5 bulan 9 hari. Nilainya lebih rendah dari umur proyek yang artinya setelah jangka waktu tersebut, perusahaan dapat mengembalikan modal yang dikeluarkan untuk bisnis usaha produksi komersialisasi jagung.

\section{KESIMPULAN}

Jumlah investasi total yang diperlukan untuk komersialisasi jagung di Provinsi Banten sebesar Rp. 19.654.890,- Hasil analisis diperoleh nilai Net Present Value (NPV) Rp. 1.713.365.673.996,- Internal Rate of Return (IRR) 115,65 persen dan Payback Period (PBP) sebesar 17,9. Dari hasil analisis tersebut menunjukkan bahwa komersialisasi jagung di Provinsi Banten layak untuk dikembangkan.

\section{DAFTAR PUSTAKA}

BAPENAS, 2009. Recana Pembangunan Jangka Panjang Nasional (2005-2025). Undang- undang Nomor 17 tahun 2007. Jakarta.

DAVID, F.R. 2007. Manajemen Strategis. Edisi ke-7 Terjemahan. PT Prenhallindo, Jakarta. Fadholi Hernanto.1985. Ilmu Usahatani. Penebar Swadaya, Jakarta.

KASRYNO, F. 2006. Suatu Penilaian Mengenai Prospek Masa Depan Jagung 
di Indonesia. Makalah disampaikan pada Seminar dan Lokakarya Nasional Jagung, 29-30 September 2006. Balai Penelitian Tanaman Serealia. Maros

MOHAMAD NAZIR. 1988. Metode Penelitian. Ghalia Indonesia, Jakarta. MUBYARTO1999. Pengantar Ekonomi Pertanian. Penebar Swadaya, Jakarta.

PORTER, M.E. 2004. Strategi Bersaing : Teknik Menganalisis Industri dan Pesaing. Penerbit Erlangga. Jakarta.

SOEKARTAWI. 1994. Teori Ekonomi Produksi dengan Pokok Bahasan Analisis Fungsi Cobb- Douglas. Rajawali Pers, Jakarta.

WHELEN, TL. DAN HUNGER2001. Strategic Management and Bussines Pollicy. Fourth Edition. Addison WesleyPublicity.USA.

ZUBACHTIRODDIN, PABBAGE MS. DAN SUBANDI,2007. Wilayah Produksi dan Potensi Pengembangan Jagung, Balai Penelitian Tanaman Serealia, Maros. 